\title{
Construção Social do Fracasso Escolar das Adolescentes em Conflito com a Lei
}

\author{
Elen Alves dos Santos ${ }^{1}$ \\ ${ }^{1}$ Universidade de Brasília, DF, Brasil.
}

\author{
Viviane Neves Legnani ${ }^{1}$ \\ ${ }^{1}$ Universidade de Brasília, DF, Brasil.
}

\begin{abstract}
Resumo: Este artigo apresenta um recorte teórico-metodológico da pesquisa de mestrado realizada com oito adolescentes em cumprimento de medida socioeducativa em uma unidade socioeducativa do Distrito Federal. Esse estudo privilegiou a concepção psicanalítica sobre a adolescência na relação com condutas infracionais e a discussão sobre a necessidade de subjetivação política de adolescentes. Objetivou-se compreender a construção do fracasso escolar na vida das adolescentes em cumprimento de medida socioeducativa. As participantes tinham de 16 a 19 anos de idade. A metodologia qualitativa ancorada em pressupostos psicanalíticos, utilizou-se de grupos de discussão e entrevistas individuais. Para análise do material recorreu-se a análise de conteúdo de Bardin (2011). Os resultados mostram que as adolescentes tiveram um histórico escolar de exclusão e autoexclusão. A discussão evidencia a necessidade tanto da escola como das unidades socioeducativas visarem um trabalho de subjetivação política, para assim, as adolescentes encontrarem pela via do coletivo, formas de reivindicação fora da criminalidade.
\end{abstract}

Palavras-chave: Adolescentes em Conflito com a Lei, Fracasso Escolar, Subjetivação Política, Psicanálise.

\section{Social Construction of School Failure of Adolescents in Conflict with the Law}

\begin{abstract}
This article presents a theoretical-methodological study of the master's research carried out with eight teenagers in compliance with socio-educational measures in a socioeducational unit of the Federal District. This study privileged the psychoanalytic conception about adolescence in the relation with conduct infractions and the discussion about the necessity of political subjectivation of adolescents. This study aimed to understand the construction of school failure in the life of teenagers in compliance with socio-educational measures. Participants were 16 to 19 years old. The qualitative methodology anchored in psychoanalytical assumptions was used for discussion groups and individual interviews. For the analysis of the material, we used the content analysis of Bardin (2011). The results show that the adolescents had a school history of exclusion and self-exclusion. The discussion highlights the need both for the school and for the socio-educational units to aim at a work of political subjectivation, so that adolescents find, through the collective way, forms of claims outside of criminality.
\end{abstract}

Keywords: Teenagers in Conflict with the Law, School Failure, Political Subjectivation, Psychoanalysis. 


\title{
Construcción Social del Fracaso Escolar de las Adolescentes en Conflicto con la Ley
}

\begin{abstract}
Resumen: Este artículo presenta un recorte teórico-metodológico de la investigación de maestría realizada con ocho niñas en cumplimiento de medida socioeducativa en una unidad socioeducativa del Distrito Federal. Este estudio privilegió la concepción psicoanalítica sobre la adolescencia en la relación con conductas infractoras y la discusión sobre la necesidad de subjetivación política de adolescentes. Se objetivó comprender la construcción del fracaso escolar en la vida de las adolescentes en cumplimiento de medida socioeducativa. Las participantes tenían entre 16 y 19 años de edad. La metodología cualitativa anclada en supuestos psicoanalíticos, se utilizó de grupos de discusión y entrevistas individuales. Para el análisis del material se utilizó el análisis de contenido de Bardin (2011). Los resultados muestran que las adolescentes tuvieron un historial escolar de exclusión y autoexclusión. La discusión evidencia la necesidad tanto de la escuela y de las unidades socioeducativas para un trabajo de subjetivación política, para así, que las adolescentes encuentren por la vía de lo colectivo, formas de reivindicación fuera de la criminalidad.
\end{abstract}

Palabras clave: Adolescentes en Conflicto con la Ley, Fracaso Escolar, Subjetividad Política, Psicoanálisis.

\section{Introdução}

No Brasil, 3,38\% (942 dos atos infracionais) foram atribuídos a adolescentes/jovens do gênero feminino. Entre todas as vulnerabilidades sociais que dão provas, os impasses no processo de escolarização mostram-se como uma realidade inequívoca (Brasil, 2018). Essas adolescentes, em sua maioria, estão inseridas em patamares socioeconômicos de baixa renda e compõem um segmento que historicamente não consegue obter do Estado uma educação de qualidade e inclusiva.

Patto (1999) realizou um estudo na década de 1980 que já sublinhava as genealogias dessa problemática. Sua análise aponta, entre outras questões, que a expansão do ensino fundamental ficou desprovida de reflexões, por parte dos educadores, sobre o papel social e político da educação. Considerando esse percurso de tempo, ou seja, quase quatro décadas, percebemos significativas mudanças nas coordenadas sociais e econômicas do nosso país. Observamos também um esforço do Estado em propor e efetivar políticas públicas para garantir, a todos, o acesso ao sistema escolar. No entanto, mesmo com poucos dados estatísticos podemos inferir a seguinte situação: um número significativo desses sujeitos tem sérios problemas na escolarização e, quando adolescentes, desistem da escola antes ou durante o ensino médio (Kuenzer, 2010).

Os motivos dessa forma de fracasso escolar são diversificados e, nesse estudo, focalizaremos em dois pontos para discuti-los: a relação pautada em preconceitos que a escola mantém com esse segmento e a finalidade da educação no contexto neoliberal contemporâneo. Nossa proposição é a de que haveria uma estreita relação entre tais questões e procuremos desdobrá-la, delineando e ilustrando, em nossa análise, o percurso escolar das adolescentes em conflito com a lei. Essa escolha foi feita porque esse segmento mostra-nos, com lentes de aumento, alguns ângulos do abandono da trajetória escolar de muitos outros adolescentes das camadas empobrecidas do nosso país, mesmo que não se envolvam com atos infracionais.

Em uma análise sobre a contemporaneidade, Coutinho (2009) elege a adolescência como o lugar do ideal cultural, pois esta etapa de vida melhor representa o culto à liberdade, o hedonismo e, sobretudo, a cultura do consumo. Nessa direção, vemos adolescentes aturdidos, em tentativas individuais ou em grupo de pares, de corresponderem a esse ideal cristalizado, sem que tenham, além deles próprios, modelos e suportes identificatórios, ou seja, haveria 
para os adolescentes o caminho de uma inflação narcísica, ocasionada pelo empobrecimento das referências que se articulam hoje no campo do ideal.

Ressalta-se que a escola é um espaço social que contribuiu para a instalação da própria noção de adolescência como etapa da vida (Ariés, 1981), por representar um ambiente privilegiado de preparação para o mundo do trabalho. Lógica adaptativa produtora de um aditamento inevitável que é o de se constituir também como um local propício para os adolescentes terem acesso, de forma reflexiva, aos conhecimentos socialmente compartilhados.

Essa finalidade crítica da educação formal foi esmaecida pelo ideário educativo neoliberal, vastamente instituído no Brasil desde a década de 1990 nas escolas públicas e nas da iniciativa privada. No entanto, esse telos é de fundamental importância para suscitar nos adolescentes um engajamento na coletividade e na sustentação do pacto civilizatório. Para Castro (2008) "as experiências de participação política podem ser 'reais' ao longo da infância e da adolescência, na medida em que esses sujeitos participam de situações de construção de espaços comuns de negociação e de luta" (p. 254), principalmente nas escolas públicas em que, necessariamente, têm que lidar com todo tipo de diferenças.

Legnani, Almeida e Beleza (2016) explicam os impactos desses processos nas instituições educativas como uma contraposição ao modelo individualista e competitivo. Para as autoras a subjetivação política pressupõe a construção de um saber acerca de ser um no mundo social, isto é, resultam dos impasses nas relações humanas quando os alunos se propõem coletivamente a uma ação voltada para algum tipo de mudança na vida institucional escolar ou em seu entorno. Ao serem tomados como parceiros sociais pelos educadores e convidados a se engajarem em prol de mudanças objetivas de melhorias, tais processos produzem, ao mesmo tempo neles próprios, mudanças subjetivas que geram consequências em suas vidas e em seus grupos sociais.

A instituição escolar, no entanto, mostra-se distante de tais questões e permanece transmitindo um ensino em que a realidade se mostra pronta e acabada, cabendo simplesmente, aos alunos, a adaptação social. Persiste, também, conforme Coutinho (2009) presa nostalgicamente ao tempo em que os professores atuavam por meio de um imaginário, cuja autoridade docente era, per si, legitimada.
Assim, em meio a uma série de sintomas sociais no campo educativo, em particular o adoecimento docente, as constantes queixas contagiosas e ressentidas dos professores em relação aos alunos e suas famílias, como também a sociabilidade violenta no interior das escolas percebemos uma opacidade de respostas diante de uma questão basilar proposta por Kupfer (2001): "qual o discurso social dominante da educação?” (p. 130). Arriscamos apontar que é o de que alunos, independentemente de seus extratos socioeconômicos, adequem-se e subordinem-se aos ditames da sociedade de consumo, o que seria visto, hoje, como a melhor forma de inclusão social. Sob essa ótica, podemos deduzir: os alunos advindos das famílias empobrecidas destoam desse ideal ou apenas se aproximam caso mostrem aos professores que podem, pela meritocracia, alcançar essa meta. Como diz Patto (1999): “o mal-estar na educação não é o mesmo nas escolas para os ricos e nas escolas para o povo" (p. 61).

Nesse contexto de mal-estar nas escolas, incluem-se as adolescentes em conflito com a lei, com histórico de reprovações e defasagens de conteúdos. Para Patto (2007), a educação voltada para os desviantes promove, na verdade, formas de "inclusão marginal" (p. 244). Nas unidades socioeducativas, persiste a tradição repressiva-assistencial, por vezes, com base na violência. Acende-se, como efeito, um sentimento de injustiça que as distancia da implicação na responsabilidade subjetiva sobre o próprio ato. Por outro lado, as instituições escolares adotam uma postura de "aceitação" dessas adolescentes no dia a dia escolar, mas sem que haja uma proposta de inclusão efetiva ou um trabalho para que possam redimensionar seus projetos de vida.

O mote educativo de ambas as instituições aponta para uma formatação social pautada em uma perspectiva moralizante, de cunho adaptativo à engrenagem da sociedade, sem promover reflexões políticas e sociais sobre o porquê do ato infracional, para além dos papéis em que normalmente oscilam entre o de serem vítimas das violências advindas do trinômio pobreza, negligência e abandono e a função de algozes precoces da sociedade (Monte \& Sampaio, 2011; Pedron, 2012; Zeitoune, 2011).

Ou seja, as reflexões propostas focam-se no âmbito individual reguladas pelos meandros da culpa e na revisão dos erros e desacertos cometidos, sem um anteparo simbólico para que as adolescentes 
em conflito com a lei possam perceber que entraram na violência real como forma de denunciar as contradições das demandas imediatistas da sociedade de consumo, cujo ideal estandardizado atrela-se a um ilusório mundo "teen". Esse "pedido de socorro" faz-se pela via da violência, como destaca Winnicott (2005) ao discutir as tendências antissociais, mas é silenciado tanto pela escola como pelas unidades socioeducativas (p. 249).

Explicitando: a engrenagem da sociedade de consumo no capitalismo tardio tem efeitos claros no crescente fenômeno da violência que acomete os/as adolescentes principalmente nas periferias e favelas do nosso país. A superprodução de bens e sua oferta no mercado só se viabilizam se houver uma rotatividade da demanda, via uma obsolescência programada. Assim, os objetos elevados à condição de garantia de um estilo ou de fetiche, são rapidamente rechaçados e, ao caírem, provocam uma "descartalização” do sujeito, aumentando-lhe a posição subjetiva de mal-estar. Para os que se veem distanciados dessa suposta completude imaginária, estipulada por um estilo sempre reinventado pela publicidade $\mathrm{e}$ mídia, a insatisfação, sentida como frustração, atinge um nível insuportável. Assim, desencadeia o dano ao outro, mediante coerção e atos violentos, de modo a resgatar o que lhes parece permanentemente fisgado.

Por isso, sublinha-se, nesse artigo, a importância de suscitar processos de subjetivação política nas instituições educativas. Legnani, Almeida e Beleza (2016) assinalam que é por meio desses processos que a angústia, sentida como interna e individual, pode ser conjeturada e analisada na relação intrínseca entre o sujeito e o social. Esse redimensionamento, em nossa proposição, pode vir a operar para que não haja reincidência nos atos infracionais.

\section{Metodologia}

A metodologia qualitativa utilizou-se dos pressupostos psicanalíticos, como a escuta ética nos encontros com as adolescentes realizados em uma unidade socioeducativa específica para as adolescentes em conflito com lei. Essa unidade está localizada em uma região administrativa (cidade-satélite) do Distrito Federal.
A pesquisa foi autorizada pela juíza da Vara da Infância e Juventude do Tribunal de Justiça do Distrito Federal. Submetida e aprovada pelo Comitê de ética do Instituto de Ciências Humanas da Universidade de Brasília ${ }^{1}$. As adolescentes foram orientadas sobre o objetivo geral da pesquisa e tiveram total garantia de sigilo de suas identidades ${ }^{2}$.

\section{Sujeitos e instrumentos da pesquisa}

Oito adolescentes, com idade entre 16 a 19 anos, alunas do ensino fundamental, todas com defasagens de séries no processo de escolarização. A rotina na unidade compreende a frequência escolar obrigatória e outras atividades como estágios e cursos profissionalizantes. Devido à rotina diferenciar-se entre as adolescentes, foram realizados grupos de reflexão e entrevistas individuais para oportunizar a participação de todas as adolescentes da unidade.

\section{Elaboração dos dados}

Os relatos das adolescentes foram transcritos na íntegra e analisados sob a ótica da Análise de Conteúdo proposta por Laurence Bardin (2011). Essa análise não se restringiu, portanto, aos conteúdos das falas, mas também aos sentidos inferidos nas construções frasais. Dessa forma, foram estabelecidos eixos para discussão a partir das seguintes questões: "O que está dizendo essa adolescente? Como isso é dito? Como as palavras, as frases e as sequências se encandeiam entre si? Qual é a lógica discursiva do conjunto?".

\section{Discussão}

As entrevistadas apresentaram em suas falas uma sequência de eventos que culminou no "fracasso escolar". Portanto, a categorização inicial das falas foi escola excludente, mundo infracional acolhedor: "a escola não acolhe, o mundo infracional sim" e, por fim, categorizou-se "o fracasso escolar e a inserção nos atos infracionais" como a melhor síntese para as construções discursivas das adolescentes.

Nessa sequência é possível observar a indiferença das escolas com as adolescentes e a ausência de sentido

\footnotetext{
${ }^{1}$ Processo no 993.671 e CAEE $n^{\circ} 39200114.1 .0000 .5540$.

${ }^{2}$ Os nomes apresentados são fictícios e optou-se em não publicizar a região urbana em que se localiza a unidade, tampouco a medida socioeducativa que cumprem, pois existem apenas duas unidades socioeducativas no DF (uma de semiliberdade e outra de internação) voltadas para as adolescentes em conflito com a lei.
} 
que atribuem à educação vinculada a outras contingências como o uso de drogas, os grupos do tipo gangues, questões de gênero $\mathrm{e}$, principalmente, os apelos das vitrines de consumo. "Nós não aguentamos ficar na sala e ficava matando aula. Porque a aula é muita chata e o professor só fala para copiar" (Janaína). "A maioria dos adolescentes param de estudar na quinta e sexta série. Assim, no ensino fundamental. A gente só estuda quando é criança eé tudo tranquilo” (Lilian). "Porque entrei no ato infracional, por fui estudar em uma escola que só tinha bandido" (Mônica). "Começa (os adolescentes em geral) matar a aula diariamente, começa a reprovar por falta e depois perde o interesse, por isso, a maioria das adolescentes está na quinta e sexta série" (Loiane).

Historicamente, a obrigatoriedade de escolarização, sobretudo de crianças e adolescentes de classes populares e negras, traz em seu bojo a meta de prevenção de criminalidade (Patto, 2007). Objetivo que se revela oposto ao esperado, pois as falas supracitadas mostram-nos que esse tipo de controle social falha pela oferta da escola de uma semiformação, tal como postula Adorno (1995). A formação (Bildung), corrobora o autor, deve visar, ao mesmo tempo, a adequação social, mas também a problematização da sociedade vigente (Bueno, 2010), para que haja transformações e mudanças. Quando se oferece uma educação atenta apenas ao amoldamento do sujeito à sociedade, isto é, uma "formação pela metade" (p. 8), produz-se, como saldo, o ressentimento nos alunos e o abandono da instituição escolar.

Essa lacuna formativa não é sem consequências. O sistema escolar ao oferecer uma educação de baixa qualidade para as camadas populares, sem que as adolescentes sejam vistas como parceiras sociais para atuarem nas transformações necessárias em suas vidas e nas suas coletividades abre o caminho para formação grupais marginalizadas no interior das escolas:

Foi com colegas da escola que eu comecei a usar maconha, matando aula. Aí, depois inventaram uma tal de família vigarista na escola e eu entrei. Esses meninos botavam o terror mesmo, tipo uma gangue, as meninas dançando funk, sempre tinha que ter pessoas usando drogas, esses negócios. Aí foi daí que eu comecei a matar aula, para curtir frevos, essas coisas, foi quando eu parei de estudar, eu fui expulsa da escola, porque essa família vigarista arrumava muita confusão na escola! Tipo, se alguém caguetasse a gente, nós pegava mesmo na saída. Eu não entrava na briga, não, mas comecei a responder professores, fiquei dando trabalho mesmo, parando na direção, comecei a ficar conhecida e depois eu fui expulsa (Bruna).

Há uma indiferença da escola com esse segmento, o fracasso escolar dessas alunas traz em seu histórico uma invisibilidade, até que adotem posturas agressivas no interior das escolas, para serem vistas e excluídas pelas suas ações. É relevante destacar, que do ponto de vista jurídico-legal, considerando o fenômeno do "matar aula" e o afastamento progressivo das adolescentes da escola, o Estatuto da Criança e do Adolescente (Lei $\mathrm{n}^{\circ}$ 8.069, 1990), preconiza que é função da escola não apenas o acolhimento do aluno, mas também o acompanhamento de sua frequência e a comunicação de suas faltas injustificadas, e os elevados níveis de repetência às autoridades competentes.

Podemos tomar esse alheamento como um tipo de violação que atinge diretamente às adolescentes. Difere-se, inteiramente, da violência que é estrutural e inevitável na educação (Kupfer, 2001). Essa consiste em uma violência simbólica, com o estabelecimento da lei, por meio da transmissão do conhecimento, que permite o pacto civilizatório, por regular a todos e ser voltada, portanto, para a coletividade e não para os desejos imediatos e individuais. Desse modo, percebe-se que com os declínios desse limite e anteparos simbólicos próprios à educação, as adolescentes entram na violência real que: "não deixa de ser uma busca fracassada como a que é feita no real, de restituir a dimensão simbólica para a regulação de suas vidas" (Kupfer, 2001, p. 145). "Você entra nessa escola primeiro [fazendo referência a escola comum] e depois você vai para a escola do crime" (Laura).

Assim, evadem da escola formal e adentram no que denominam de "escola da criminalidade". Em um dos nossos encontros a música "Só diretoria" da tribo da periferia foi cantada em voz coletiva:

Na minha escola não tem professor é só diretoria Ninguém hoje mais entra que o portão fechou Ésó diretoria [...] caretaloca, foda-sequem criticou [...]. Mais disciplina. Que hoje a rua traz aula de química.

\footnotetext{
${ }^{3}$ As frases em itálico são as transcrições literais da entrevista.
} 
A escola contemporânea privilegia a competitividade entre os adolescentes e não valoriza as questões relativas à solidariedade social. Nessa perspectiva, as relações interpessoais são tensionadas e as alunas que não conseguem entrar nessa rivalidade buscam na rua ou na violência um lugar em que possa pertencer e mostrar seu valor fálico, ou seja, mostrar o poder para a sociedade (Legnani, D’ Aragão, Spinola, \& Paladino, 2012).

Quando eu comecei a usar drogas, eu nem estava mais na escola, porque tipo assim, professor, diretor, os alunos tinham bullying. Estudar para que? Teve uma vez, eu fui falar com o professor e fui levar caso na direção, porque os alunos estavam malhando de mim, do meu tamanho e ficavam falando que eu era gorda, feia e também porque eu sou preta, muita gente ficava com bullying comigo. Eu cheguei na direção, e eles chamaram a professora, no outro dia, essa professora chegou na escola com setes pedras em cima de mim, me xingando toda. Desde daí eu comecei a desistir da escola, porque se professor e diretor não liga, eu fazer o que na escola, me diga? (Patrícia).

Nos grupos de reflexão também foi interessante observar no diálogo das adolescentes a adoção do "discurso competente" da escola, ou seja, um discurso com estatuto de conhecimento legítimo que produz, por consequência, os "incompetentes", como denomina Patto (2006). Isto é, as adolescentes incorporam os discursos articulados nos ambientes educativos: "Gente! A gente não para de estudar por causa da escola, não. A gente para porque a gente se envolve com a rua!" (Lilian).

Se você falar: hoje, eu vou estudar, tenho certeza que o professor vai te ajudar! A gente tem que querer em primeiro lugar, se você falar, chegar para o professor e falar: professor, eu estou com tanta dificuldade na sua matéria, vem cá me ensina. O professor vai te dizer: vem cá que você quer vencer, eu vou te ajudar! Se um professor te falar que está lá, só por causa do dinheiro dele, e mentira, pois ele não está lá só para isso (Jordana).

Também salientam que não estudam por ausência de apoio familiar. Assim, repetem o discurso "dos mes- tres", os quais, de forma recorrente, fazem menção às "famílias desestruturadas" como a causa primordial do fracasso escolar. Como resultado da incorporação do discurso da escola, percebem-se, então, como culpadas por não conseguirem aproveitar a chance de ascensão social oferecida pela escolarização. "Na verdade, se nós não estudar, o que vai ser de nós nesse mundo?

[...] Você sabia que hoje para você varrer a rua, você tem que ter o ensino médio" (Carla) "Se com estudo já é difícil, imagine sem estudo. Tem que estudar pelo menos para ter alguma coisa? Para ter as coisas, para ser inteligente” (Ângela).

Segundo Baudrillard (2009) haveria uma estreita analogia entre a proposta da escola e a ideologia do consumo, pois ambas trazem em seu bojo a ideia de superação das condições sociais. Dessa forma, todos teriam acesso à escolarização e aos bens de consumo, porém essa igualmente é apenas formal e abstrata, mas, por ser supostamente oferecida a todos, opera como a principal forma de discriminação social para os que não conseguem "seu lugar" nesse mundo.

Discriminação que produz o sentimento de vergonha, como aponta Gaulejac (2006): "Nas sociedades que louvam a excelência, o desempenho e o enriquecimento como valores essenciais, a pobreza é percebida como um fracasso pessoal [...]. A pobreza é vergonhosa porque a riqueza é sinal de êxito" (p. 84).

Estou na $5^{\text {a }}$ série, isso é uma vergonha para a sociedade! É uma vergonha! Eu tiro pela minha amiga, ela vai fazer 17 anos, já entrou para fazer agronomia, ela se afastou de mim, porque senão ela ia se queimar. Totalmente, mudada já terminou os estudos dela. E eu estou aqui na quinta série parada na vida, andando para trás, porque isso é só andar para trás. Porque andar para frente só se eu estivesse crescendo (Jordana).

O autor clarifica o sentimento de vergonha por meio dos processos de identificação e reprodução. A identificação ocorre de forma inconsciente com o "outro fracassado", por sua vez, a reprodução é uma repetição subjetiva do que é visto socialmente como ser um pária na sociedade. Gaulejac (2006) reitera que não são elementos da experiência do sujeito isolados que causam a internalização da vergonha, mas sim aquelas gradativas que imbricam angústia, desejo e a invalidação da expressão do sujeito. 
Quando eu entrei no crime, eu me sentia como se eu tivesse desrespeitando a sala de aula, eu tava lá, mas eu só queria saber de fumar drogas, se dependesse de mim, eu fumaria um na sala de aula. Do jeito que eu estava, já estava me fazendo mal, eu fui desistindo (Milena).

As adolescentes, como vimos se excluem do ambiente escolar, por não se sentirem à altura desse sistema. Também incide sobre a problemática da evasão o enfoque moralista adotado por essas instituições quanto ao uso de drogas. Normalmente, a intervenção da escola é de mera repressão, sem se atentar para a promoção de saúde que esses casos demandam. De fato, como assinala Cruz (2014) abordar o uso de drogas na sociedade atual é um trabalho árduo, em função dos tabus e dos preconceitos. Veicula-se, na mídia sensacionalista, por exemplo, a ideia de que os usuários seriam os maiores culpados pela violência nas cidades. Assim, essas concepções deterministas e fatalistas invadem o universo escolar, que apenas repete, sem criticidade, a conduta da nossa da sociedade em face dos usuários. Um exemplo são os livros pedagógicos que tecem como foco os efeitos prejudiciais e nocivos das substâncias ilícitas, enquanto fecham os olhos para o uso alarmante e indiscriminado das drogas lícitas, inclusive incentivado pelas escolas para controlar o comportamento de muitos alunos (Cruz, 2014).

Desvalem, portanto, a historicidade do uso de drogas pela humanidade, as sensações de prazer proporcionadas, as transgressões simbólicas, abolindo, assim, qualquer diálogo efetivo sobre essa problemática, de modo a afastar os estudantes de uma relação mortífera com a drogadição (Marquez, 2013). Assim, é um equívoco inexorável eximir-se dessa discussão nas escolas, pois abdicar dessa reflexão com os/as adolescentes serve à alienação frente a essa problemática e a manutenção de uma posição ainda mais marginalizada e de risco social.

Eles (professores) estavam era achando bom terem tirado mais um "noiado" da escola. Tinha um aluno a menos bebendo água, menos um aluno comendo, menos um gastando energia, menos tudo. Eu era só mais uma no meio da multidão. Eles não ligam, o salário deles vai cair todo mês (Milena).
Legnani, Almeida \& Beleza (2016) afirmam que a conduta escolar de convidar os alunos como parceiros sociais para confrontar seus dilemas subjetivos junto às questões cotidianas que os interpelam produz chances para que os(as) adolescentes assumam responsabilidades frente aos seus atos, para além de uma posição servil e infantilizada frente ao outro social. As autoras ampliam a noção freudiana de $e d u$ cação para realidade ao pensá-la na contemporaneidade e apontam que os educadores são responsáveis por clarificarem às crianças e aos adolescentes acerca da condição de objeto que a sociedade tende a lhes colocar.

De acordo com os dados levantados, diante das experiências que se iniciam com as formações de gangues e o uso de drogas ilícitas, a evasão da escola se finda quando as adolescentes começam a cumprir as medidas socioeducativas, pois há, independentemente da medida a ser cumprida, obrigatoriedade de escolarização para todos os adolescentes em conflito com a lei. "Aqui eu vou para aula, né? Porque se não, eu perco meu final de semana. Eu só vou para assistir a aula mesmo, porque eu já estou reprovada" (Janaína). "Essa é podre, desinteressante, não tem nada de legal, podre mesmo! Eu não vou mentir só estou estudando nela para não ficar sem estudar! Quando eu estiver melhor, vou pagar uns estudos para mim" (Jordana).

Vemos nos relatos das adolescentes que a escola se torna então um lugar de obrigatoriedade esvaziado de sentido. Paira, inclusive, a dúvida se o ensino público ofertado é de qualidade. Também tecem críticas agudas ao aparato jurídico do sistema socioeducativo: "A justiça... porque a justiça é complicado, por exemplo quem mata fica pouco tempo, até para quem é de maior e quem mexe com o tráfico fica mais tempo" (Janaína); "A justiça é uma farsa, é irônica, por isso que nós fazemos nossas próprias leis [...]. Eu falo é da lei da sobrevivência. As leis que existem não ajudam a gente, nós temos que criar as próprias leis para sobreviver" (Emily).

Podemos inferir, por meio desses relatos que oscilam entre culpa ou acusações à escola e ao sistema socioeducativo que falta um espaço de escuta para essas adolescentes nas instituições. Rassial (1999), afirma que o acting-out caracteriza-se por ser um endereçamento ao outro sem palavras, ou seja, é uma ação que "fala" ao outro. Esse "momento louco" (Benhaim, 2008) consiste em não poder fazer 
de outra maneira se não pela via do ato é, na verdade, o que impede um derradeiro desmoronamento subjetivo. "É porque era ser só um assalto, mas acaba que deu em sequestro. Era só para assaltar, levar o carro o dinheiro que a pessoa tinha" (Loiane). "Eu não sei o que se passava na minha cabeça., mulher! Até eu queria saber o que se passava na minha mente!" (Emily).

Winnicott (2005) aponta a tendência antissocial como apelo a um holding apaziguador das tensões internas produzidas por um sentimento de perda relativo a algum objeto que anteriormente implicava em conforto e proteção. Essa sustentação não opera quando se aposta nos "nãos" como forma de limites, sem referências que permitam as adolescentes enxergar um "sim", ou novo percurso subjetivo e social.

Como defesa, em grupos de pares, constroem suas próprias leis e permanecem em um laço social de confronto. A violência, para elas, é uma espécie de bumerangue, pois vai e volta, registrado em seus corpos, as marcas das brigas, dos tiros por disputas por território. "É, não tem papai e mamãe para dar o que nos quer não" (Janaína). "O crime não é creme, o diabo não amacia ninguém. Entro no crime, entro na lei da malandragem, vacilou, leva [...]. Infelizmente, estou aqui em uma cela fria, lotada de pilantragem, tem que ser ligeiro, sem dar mole" (Mônica).

É a lei da malandragem, é viver na lei da malandragem [...] E nós somos da lei da malandragem. Se nós vê um rico a gente quer roubar, porque eles vão ter de novo, toda hora e nós não, é difícil a gente conseguir (Emily).

Por fim, as diferenças socioeconômicas também foram enfatizadas na fala das adolescentes. É por meio destas que justificam os atos infracionais para obtenção de bens de consumo. Em particular, para que possam sustentar o "ser mulher" na sociedade. Os significantes como beleza, produtos mercadológicos, roupas de marca, joias circulam de forma recorrente nas construções discursivas das adolescentes. "Eu ganhava muito dinheiro [...] por dia, por semana! Final de semana era mais, aí eu comprava roupa para mim” (Ângela).

Ah, eu comprava roupas, drogas, essas coisas. Porque, assim, meu pai recebia aposentadoria e como eu não queria ficar pedindo as coisas para ele, porque ele já ajuda muito a gente, nunca foi de faltar as coisas para mim não, sabe? Mas, sempre você ver alguma roupa que você quer, uma coisa que você quer e seus pais não podem te dar e aí eu comprava roupas, drogas, celular, tudo (Bruna).

Do Carmo e Rosa (2013) discutem que na adolescência contemporânea, além do trabalho da árdua reelaboração psíquica exigida nessa etapa de vida não existem rituais de passagem para a vida adulta. Assim, é o eu ideal que triunfa, sendo que este não exige um movimento subjetivo como é demandado pelo ideal-do-eu, ou seja, um movimento que requer um tempo de espera em prol do desejo (Freud, 1976a). Por isso, o gozo como decorrente do consumo, advindo das condutas infracionais é sedutor: "tudo que desejo, eu posso". "Mas, eu gosto muito é de ostentar, eu gosto do que é bom. Ostentar, para mim, é ter um relógio bom, tênis, roupa. Eu paguei um tênis de mil e pouco! Comer bem, uma roupa boa" (Jordana). "Aonde, moço que eu ganhava como agora no estágio por mês? Eu ganhava era em um só dia!" (Loiane). "Sei lá, para comprar roupa, para comprar um monte de coisas, roupas de marca, sandálias, tênis, tudo mulher! Tudo que é bom!" (Ângela).

Na minha vida, minha mãe sempre me dá o que eu preciso para viver, dá para sobreviver com o que ela me dá, ela não me dá o que eu quero, mas, aí por questão de que eu sempre quero mais, para ter o peguete da hora, para curtir meus frevos, minhas drogas, eu fui e entrei nessa vida. Aí eu aprendi várias coisas, como abrir carros, casa, vítima na rua, e aí eu roubei, roubei, roubei, até rodar e chegar aqui para contar a história, pelo menos estou viva para contar a história (Mônica).

A fala de uma das adolescentes mostrou-se significativa em relação aos apelos do universo do consumo. Emily disse: "eu cansei de olhar essas revistas, só tem rico". Criticou, assim, a representatividade da publicidade que não cessa de não exibir a "cara da riqueza" (expressão das adolescentes). Nessa direção, salienta-se o papel social da educação escolar para questionar, pela via histórica, os estereótipos decorrentes dos modelos culturais elitizados propagados na mídia. É notório: o mito de felicidade atrela-se às pessoas de cor branca, com objetos de consumo caros e posições estereotipadas de gênero. Dessa forma, compete à escola não poupá-las dessa questão e apontar os interesses históricos, econômicos e sociais subjacentes a essa hegemonia. 
No que tange à relação entre papéis de gênero e atos infracionais. Ressalta-se, que as adolescentes revelam desejar o reconhecimento dos homens no lugar de "princesas", ou seja, relatam que estar fora desse lugar estipulado às mulheres seria mais um fator de exclusão nas suas vidas. Esse reconhecimento refere-se, sobretudo, à obrigatoriedade de beleza.

Rodoviária é para os necessitados, vender droga assim na sociedade para todo mundo ver é feio, é ridículo. Você me vê toda arrumada na rodoviária, em uma roda, com um bando de viciados, mendigo, machos, só eu de mulher, você vai olhar para mim e vai falar o que? Aquela é uma bandidona! Não é feio? (Jordana).

Assim, nós somos mais arrumadinhas. Tem esquina que você vai e diz: cara. Não acredito que essa menina é dessa vida, tem muitas meninas bonitas. Noiada? Se você ver o tanto de meninas noiadas bonitas que quando começam a fumar a pele fica tão feia. Então, é andar mais arrumada, estar mais de boa (Bruna).

Assim, mesmo você lá no corre, vendendo sua droga, ficar falando "caralho", mais que bandido! Pererê, parará, conversa vai, conversa vem, abrindo sua boca, armada o tempo todo, os caras vão olhar e falar: Caralho! Essa quer ser mais bandida que eu! Eu não pego ela nunca! Primeiro, que bandido não gosta de bandida, a gente já tira por aí, todas nós sabemos disso! a gente sabe muito bem disso! (Bruna).

Desse modo, as adolescentes transitam nesses papéis de gênero, entre ser "princesa" e ser "bandida". Destaca-se que a adolescência compõe inúmeros momentos de dúvidas narcísicas e simbólicas, fase que aponta para uma pane, especificamente de refundação identitária. Guerra, Cunha, Costa \&, Silva (2014) discutem que além das questões adolescentes, saber como operar o ser mulher e estar na criminalidade é mais um desafio para essas meninas.

A visão das adolescentes sobre o papel da mulher na sociedade demonstra o que Navarro-Swain (2006) e Lagarde (2011) esclarecem: a subjetividade, a capacidade laborativa, a sexualidade e a estética das mulheres, desde o nascimento, foram engendradas pela sociedade patriarcal, que definiu o que é ser mulher em referência ao homem como um representante hie- rárquico nas relações de poder. Vimos nos relatos das entrevistadas também essa subjugação para serem alvo do desejo e olhares masculinos, essas construções que validam o estereótipo do que é ser mulher. "Na verdade, eles não vai aceitar que a gente seja mais bandida que eles" (Lilian). "A gente pode até ser mais mala que eles, mas a gente não demonstra" (Jordana).

De forma geral, as falas das adolescentes destoam das pesquisas que mostram a participação das mulheres para despistar policiais ou vítimas enquanto os homens ativamente atuam na conduta criminal. Assim, podemos sintetizar: elas roubam ou traficam para serem "princesas" para não destoarem do que é "ser mulher". Nas práticas infracionais tentam agradar os parceiros por meio de uma conduta dissimuladamente passiva, também representativa do papel "ser mulher" em nossa sociedade.

Em síntese, diante da deserção dos debates sobre as questões de gênero, drogas e consumo nas instituições responsáveis por suas ressocializações adentram em uma espécie de cativeiro, ou seja, em um ciclo repetitivo nas condutas infracionais que as remete a novas medidas socioeducativas. Salientamos ao longo dessa discussão a omissão das escolas em face das questões cruciais que afetam as adolescentes das camadas empobrecidas do nosso país que praticam atos infracionais. A falta de engajamento, por parte da escola, em um ensino crítico pautado no compartilhamento do conhecimento socialmente construído, mostra-se contundente.

Vimos que as adolescentes abandonaram a escolarização e foram gradativamente capturadas por uma posição marginalizada na sociedade. Como consequência, tentaram fazer uma adaptação social por meio das práticas infracionais com o objetivo de inserção na sociedade de consumo, com a obtenção de bens direcionados à construção mercadológica da "beleza feminina”. Desse modo, as adolescentes consideravam "perder tempo nos estudos" e "ganhar o tempo" na prática de atos infracionais para obter os meios que supostamente lhes garantiriam a imagem estereotipada pela mídia de "mulheres belas e desejadas".

Dessa forma, considera-se que a escola precisa intervir junto às educandas adolescentes problematizando a sociedade que vivem, tendo-as como parceiras para questionar e reconfigurar o contexto social, para isso é fundamental abdicar dos paradigmas moralistas e meramente punitivos.

Frisou-se que as adolescentes relataram-se como “indignas" na escola, devido à prática dos delitos. Essa 
culpa mostra-se, no limite, improdutiva, pois sabem também da postura excludente dessa instituição junto a todos que desviam da imagem de aluno ideal. Esse movimento oscilante detectado nas falas das entrevistadas mostra como o fracasso escolar foi sendo construído em suas vidas por falta de um anteparo social que poderia ter sido feito na escola, sem que essa instituição se deslocasse da sua própria função.

\section{Considerações finais}

Essa pesquisa destacou que a formação escolar quanto mais crítica for, mais pode se constituir como um meio eficaz para não haver reincidência nas práticas infracionais por parte das adolescentes em conflito com a lei. Nossa proposição é que não cabe aos educadores ocuparem nenhuma outra posição a não ser a de professores que ensinam, mas é fundamental torná-la reflexiva para atuarem com esse segmento, como também junto aos alunos das camadas empobrecidas. Reflexão que se inicia com uma questão basilar: qual a finalidade do ato educativo nas escolas, considerando as diferenças socioeconômicas acintosas do nosso país?

No sistema socioeducativo aponta-se, por sua vez, também a necessidade de grupos de debates e reflexões entre educadores sociais, psicólogos e assistentes sociais junto a essas adolescentes. Castro (2008) afirma que são ínfimos os espaços na sociedade para que crianças e adolescentes coloquem-se como sujeitos do discurso. Portanto, entendemos como fundamentais suscitar nessas instituições os processos de subjetivação política para levar as adolescentes em conflito com a lei, por meio de suas próprias experiências, "a interrogarem-se sobre o que está inadequado e difícil na convivência humana ao seu redor" (Castro, 2008, p. 255). Esses processos, quando propostos de forma horizontal com livre circulação das palavras dos sujeitos não são arriscados, tampouco levam à desadaptação social; ao contrário, levam às contestações canalizadas em atos em defesa da coletividade, da justiça e da emancipação.

Abdicar nessas instituições de uma postura rígida vertical ehierárquica não éuma tarefa fácil. Freud (1976b) em "Algumas reflexões sobre a Psicologia Escolar", alerta que para se educar é necessária a reconciliação com a criança que se foi. Entendemos que essa reconciliação também é essencial para todos que atuam com os adolescentes em conflito com a lei para que ultrapassem a postura moral, recordando das inseguranças, das transgressões, dos dilemas nessa etapa da vida.

O intuito da psicanálise ao propor uma educação para a realidade é o de pensar uma postura ética para os educadores. Postura que não se esquiva diante da complexidade do mundo, tampouco cria um muro entre os adultos e crianças e adolescentes. A função do adulto é mostrar a esses sujeitos como é o mundo Arendt (1997) e não projetar sobre eles um futuro idealizado, conformando o ato educativo a um hipotético tempo posterior. Podemos inferir, também, tratar-se de uma educação avessa ao tamponamento da liberdade de pensar. Freud considera um erro implacável poupar o outro do acesso à verdade, por mais inumana que ela possa parecer, pois tal tamponamento não teria outra função a não ser a de mantê-los em posição de objeto, sem que se consiga ocupar a posição de sujeito, responsabilizando-se pelos próprios atos.

Assim, na perspectiva da educação para a realidade, deve-se propiciar o esclarecimento das questões nebulosas que envolvem a exploração e coisificação dos homens na sociedade de consumo. A ilusão, nessa empreitada, não tem valor e não condiz com a realidade da condição humana. Portanto, acreditamos que esse entendimento precisa ser inserido nas escolas e, sobretudo, nas unidades de atendimentos às adolescentes em conflito com a lei. O objetivo não pode ser a adaptação e a mera inserção via trabalho para que o/a adolescente possa se tornar um "consumidor" por adquirir o produto com seu trabalho. Será esse o caminho? Para os e as adolescentes não seria mais fácil ter tais objetos tão absolutamente descartáveis advindos das condutas infracionais?

Com as contribuições da Psicanálise entende-se que uma das funções dos profissionais dessas unidades é usufruir do potencial crítico dos grupos e fazer deles uma potência para que os adolescentes se percebam como integrantes de uma sociedade desigual, mas que, por pode ser transformada, através de suas ações, desde que canalizem a revolta e ampliem o pensamento coletivo.

\section{Referências}

Adorno, T. W. (1995). Educação e emancipação. São Paulo, SP: Paz \& Terra. 1995.

Arendt, H. (1997). Entre o passado e o futuro (4a ed.). São Paulo, SP: Perspectiva. (Originalmente publicado em 1954). 
Ariés, P. (1981). História social da infância e da família. Rio de Janeiro, RJ: Zahar.

Bardin, L. (2011). Análise de conteúdo (L. A. Reto, \& A. Pinheiro, Trad.). São Paulo, SP: 70.

Baudrillard, J. (2009). A sociedade de consumo. Lisboa: 70.

Benhaim, M. (2008). O materno e a delinqüência. Ágora: Estudos em Teoria Psicanalítica, 11(1), 9-16. https://doi.org/10.1590/S1516-14982008000100001

Brasil. (2018). Ministério dos Direitos Humanos. Levantamento anual Sinase 2016. Brasília, DF: Ministério dos Direitos Humanos, 2018. Recuperado de https://www.mdh.gov.br/todas-as-noticias/2018/marco/Levantamento_2016Final.pdf

Brasil. (2012). Presidência da República. Secretaria de Direitos Humanos. Levantamento anual dos/as adolescentes em conflito com a lei. Brasília, DF: o autor. Recuperado de http://www.sdh.gov.br/assuntos/criancas-e-adolescentes/programas/sistema-nacional-de-medidas-socioeducativas/levantamentos-anuais

Bueno, S. F. (2010). Educação, paranoia e semiformação. Educação em Revista, 26(2), 299-315. https://doi. org/10.1590/S0102-46982010000200014

Carmo, V. C. S., \& Rosa, M. D. (2013). O laço social na adolescência: a violência como ficção de uma vida desqualificada. Estilos da Clínica, 18(2), 297-317.

Castro, L. R. (2008). Participação política e juventude: Do mal-estar à responsabilização frente ao destino comum. Revista de Sociologia e Política, 16(30), 253-268. https://doi.org/10.1590/S0104-44782008000100015

Coutinho, L. G. (2009). Adolescência e errância: O laço social na contemporaneidade. Rio de Janeiro, RJ: FAPERJ.

Cruz, J. P. C. (2014). Concepções de estudantes de pedagogia e professores da rede pública sobre a problemática das drogas nas escolas (Monografia de conclusão de curso). Universidade de Brasília, Brasília, DF, Brasil.

Freud. S. (1976a). Totem e tabu. In: S. Freud, Obras psicológicas completas de Sigmund Freud. (edição standard brasileira, vol. 13). Rio de Janeiro, RJ: Imago. (Originalmente publicado em 1913).

Freud. S. (1976b). Algumas reflexões sobre a psicologia do escolar. In: S. Freud, Obras psicológicas completas de Sigmund Freud. (edição standard brasileira, vol. 13). Rio de Janeiro, RJ: Imago. (Originalmente publicado em 1914).

Gaulejac, V. (2006). As origens da vergonha. São Paulo, SP:Via Lettere.

Guerra, A. M. C., Cunha, C. F., Costa, M. H., \& Silva, T. L. (2014). Risco e sinthome: A psicanálise no sistema socioeducativo. Psicologia: Teoria e Pesquisa, 30(2), 171-177. https://doi.org/10.1590/S0102-37722014000200006

Kuenzer, A. Z. (2010). O ensino médio no plano nacional de educação 2011-2020: Superando a década perdida? Educação \& Sociedade, 31(112), 851-873. https://doi.org/10.1590/S0101-73302010000300011

Kupfer, M. C. M. (2001). Educação para o futuro: Psicanálise e educação. São Paulo, SP: Escuta.

Lagarde. M. (2011). Los cautiverios de las mujeres: Madresposas, monjas, putas, presas y locas. Ciudad de Mexico: UNAM.

Legnani, V. N., Almeida, S. F., \& Beleza, F. (2016). Processos de subjetivação política nas escolas: Relatos de experiências em mediação social. In: K. Brasil, D. Drieu (Org.), Mediação, simbolização e espaço grupal: Propostas de intervenções com adolescentes vulneráveis (pp. 33-51). (v. 1). Brasília, DF: Liber.

Legnani, V. N., Aragão, S., Spinola, J. M., \& Paladino, L. M. (2012). Grupos de adolescentes no espaço escolar: O papel do professor face às fratrias adolescentes. Linhas Críticas, 18(35), 209-226.

Lei No 8.069, de 13 de julho de 1990. Dispõe sobre o estatuto da criança e do adolescente e dá outras providências. Diário Oficial União, 16 jul. 1990.

Marquez, M. O. (2013). Educação escolar sobre drogas: O sujeito do inconsciente e o fenômeno da toxicomania (Dissertação de Mestrado). Universidade Federal de Goiás, Goiânia, GO, Brasil.

Monte, F. F. C., \& Sampaio, L. R. (2012). Práticas pedagógicas e moralidade em unidade de internamento de adolescentes autores de atos infracionais. Psicologia: Reflexão e Crítica, 25(2), 368-377. https://doi.org/10.1590/S010279722012000200019

Navarro-Swain, T. (2006). Entre a vida e a morte, o sexo. Revista Labrys Estudos Feministas, 10.

Patto, M. H. S. (2007). "Escolas cheias, cadeias vazias" nota sobre as raízes ideológicas do pensamento educacional brasileiro. Estudos Avançados, 21(61), 243-266. https://doi.org/10.1590/S0103-40142007000300016

Patto, M.H.S. (2006).Apresentação. Psicologia USP, 17(1), 11-16.https:// doi.org/ 10.1590/S0103-65642006000100002 
Patto, M. H. S. (1999). Ética e mal-estar na educação: apontamentos para uma reflexão. Anais do I Colóquio do Lugar de Vida. São Paulo, SP: USP.

Pedron, L. S. (2012). Entre o coercitivo e o educativo: Uma análise da responsabilização socioeducativa na internação de adolescentes em conflito com a lei (Dissertação de Mestrado). Faculdade de Educação, Universidade Federal de Minas Gerais, Belo Horizonte, MG, Brasil.

Rassial, J. J. (2000). O sujeito em estado limite. Rio de Janeiro, RJ: Companhia de Freud.

Winnicott. D. (2005). Privação e delinquência. (2a ed.). São Paulo, SP: Martins Fontes. (Originalemente publicada em 1963).

Zeitoune, C. M. (2011). A clínica psicanalítica do ato infracional: Os impasses da sexuação na adolescência. Psicanálise \& Barroco em Revista, 9(2), 117-134.

Elen Alves dos Santos

Psicóloga. Mestre em Educação pela Faculdade de Educação da Universidade de Brasília. Doutoranda em Psicologia pela Universidade de Brasília. Docente no Ensino Superior. Brasília - DF. Brasil.

E-mail: elenpsi@gmail.com

(iD https://orcid.org/0000-0001-8850-2117

Viviane Neves Legnani

Psicanalista. Mestre e Doutora em Psicologia pela Universidade de Brasília. Pós-Doutorado pela Universidade Católica de Brasília. Docente na Faculdade de Educação da Universidade de Brasília. Brasília - DF. Brasil.

E-mail: vivilegnani@gmail.com

(iD) https://orcid.org/0000-0001-6362-1443

Endereço para envio de correspondência:

Centro Empresarial Norte, sala 609, bloco B.

Brasília - DF. Brasil.

Recebido 21/05/2017

Reformulado 02/05/2018

Aceito 07/05/2018

Received 05/21/2017

Reformulated $05 / 02 / 2018$

Approved 05/07/2018

Recibido 21/05/2017

Reformulado 02/05/2018

Aceptado 07/05/2018

Como citar: Santos, E. A., \& Legnani, V. N. (2019). Construção social do fracasso escolar das adolescentes em conflito com a lei. Psicologia: Ciência e Profissão, 39, 1-12. https://doi.org/10.1590/1982-3703003180302

How to cite: Santos, E. A., \& Legnani, V. N.. (2019). Social construction of school failure of adolescents in conflict with the law. Psicologia: Ciência e Profissão, 39, 1-12. https://doi.org/10.1590/1982-3703003180302

Cómo citar: Santos, E. A., \& Legnani, V. N. (2019). Construcción social del fracaso escolar de las adolescentes en conflicto con la ley. Psicologia: Ciência e Profissão, 39, 1-12. https://doi.org/10.1590/1982-3703003180302 